\title{
USE OF THE THEORY OF GAMES AS AN INNOVATIVE METHOD IN THE SOLAR ENERGY INVESTMENT DECISION PROCESS
}

\section{USO DA TEORIA DOS JOGOS COMO MÉTODO INOVADOR NO PROCESSO DECISÓRIO DE INVESTIMENTO DA ENERGIA SOLAR}

M. S. L. S. TOMAZ ${ }^{1}$, L. S. CASTRILlO ${ }^{1}$, D. C. D. CUNHA ${ }^{1}$, A. E. A. G. FRANÇA ${ }^{1}$ and E. H. D. FITTIPALDI $^{1}$

${ }^{1}$ University of Pernambuco, Polytechnic School of Pernambuco, Post-Graduation Program in Energy Technology, Recife, Pernambuco, Brazil, monikii007@ hotmail.com

\begin{tabular}{l} 
A R T I C L E I N F O \\
\hline Article history: \\
Received 2018-11-30 \\
Accepted 2018-12-03 \\
Available online 2019-03-08 \\
pa lavras - chave \\
Competição \\
Energia solar \\
Investimento \\
Modelo de Cournot \\
Teoria dos jogos \\
$k$ e y wo r $d s$ \\
Competition \\
Solar energy \\
Investment \\
Cournot Model \\
Theory of Games \\
\hline
\end{tabular}

\begin{abstract}
A B S T R A C T
Brazil is a country with high solar energy potential due to the vast unhabitaded areas close to the Equator with high availability of solar radiation. With a simple setting, low maintenance costs, sustainability appeal and an inexhaustible power supply, the solar plants have been transformed in attractive investments in the electrical power sector. In the Brazilian Northeastern region, it's possible to find the best conditions for the development of new solar plants due to the climate, dry and sunny all year. The present work aims to present the use of game theory as an innovative method in the investment decision process between two companies of solar energy generation in Northeastrn region of Brazil. The methodology used for this analysis was the Cournot method to conclude whether competition or cooperation among the agents involved prevails in the market.
\end{abstract}




\section{INTRODUCTION}

The Game Theory has the objective of analyzing situations where the results of individual actions or institutions rely substantially on the actions of other individuals, that is, deals with situations where no character can conveniently make decisions without taking into account the possible decisions of others. (FIGUEIREDO, 1994).

A game can be exposed mathematically in different ways, according to its properties and goals. The most detailed way to present a game is in its most extensive form in which its description is concentrated on its sequential movement. In this format, decisions are made one after another. The strategy concept taken as the complete description of how a person participating in a game can act under any circumstances, The concept of strategy taken as the complete description of how a person participating in a game may act under any circumstances, or any course of action of an agent in a game in the extensive manner, allows us to define and express the game in a manner more simple and objective, and therefore of greater theoretical importance, called normal form or strategic form. (FIGUEIREDO, 1994).

There are two other points that should be highlighted during a modeling in the strategic form is the fact that each player can ignore the decision of the other at the time he makes his decision and not worry about the time after the decision making, ie, players only consider the immediate consequences during the decision. These two aspects characterize a simultaneous game.

The application of Game Theory in the national electrical scenario should be an alternative decision making. During the restructuring of the sector, which began to be decentralized, a competition is promoted between generators and distributors of electrical power. In the mixed model, which includes state-owned and private companies, the implementation of offer bids for the determination of the spot price is under discussion, as is already the case in several countries.

In this context, companies constitute a new environment, competing for the quantity of electric energy to be available in the market and the prices, both through bilateral contracts and in the spot market, as well as through new ventures. This competition is not simple, since the actions of a market agent depend on the actions of other agents. What we have is a game of cross-interests, in which each agent seeks to maximize its benefits, which are not simply about market share, but about corporate profits. The Game Theory finds direct application in this conflict of interest and can be used under two different points of view in electric energy markets: that of the agent and that of the regulator agency. The first aims to maximize its profit and the second to ensure the proper functioning of the market.

The considerations presented motivated the objective of this article for the presentation of the analysis of the behavior of two agents in the market of solar electric energy in the Northeast of Brazil, using Game Theory. For this, the
Cournot Model was used with two companies and it is sought to conclude whether competition or cooperation among the agents involved prevails in the market.

\section{LITERATURE REVIEW}

\subsection{A brief history of Game Theory}

In 1838, the mathematician, philosopher and economist from France, Antoine Cournot (1801-1877), published the Cournot Model, which consists of an analysis of the behavior of two industrial companies which decided to simultaneously plan their production, creating the introduction of a duopoly.

In 1928, another mathematician, Jon von Neumann created what is known as the Minimax Theorem. Neumann showed interest in economy and along with the economist Oscar Morgenstern, published the classic "The Theory of Games and Economics Behavior" in 1944, and, with this, the Game Theory invaded the field of applied economics and mathematics.

In 1950, the American mathematician John Forbes Nash Jr, published four important articles for the Game Theory. In "Equilibrium Points in n-Person Games" and "Non-cooperative Games", Nash proved the existence of a mixed strategy equilibrium for non-cooperative games, called Nash equilibrium, and suggested an approach to cooperative game studies, from its reduction to noncooperative form.

\subsection{The market power}

Market power is the ability of an economic agent to keep its prices above the competitive level or to improve market penetration in order to maximize its profits by getting more clients or more profitable customers.

What could be observed in England, and partly in Brazil, in the creation of the electric power market, was the breakdown of the vertical integrated monopoly, creating a horizontal market and reducing market power (LANZOTTI, 2002). Even so, a degree of power remains, which will depend on how the market was subdivided. Transmission constraints, in turn, tend to divide the market into submarkets and may lead to high degrees of concentration of market power in these submarkets. In addition, companies in strategic locations can clog flows in these interconnectors to create scarcity in submarkets and raise prices.

\subsection{Game Theory applied to oligopolistic models}

The Game Theory can be used in two different perspectives in an electricity market. The first would be from the point of view of the regulatory body, which, through the application of oligopoly models to the respective market, could supervise how its agents are behaving, whether the predominant has been cooperation or competition between agents, as this directly influences market prices.

The second perspective would be the vision of a certain agent whose objective is to choose a strategy, so that its 
performance in the market maximize its profit. To do this, this agent would use Game Theory as a tool to predict the strategies of its competitors, based on information it has about the market and strategies used by its competitors in the past. Then, with the set of expectations for the strategies of their opponents at hand, this agent would solve an optimization problem, potentializing its benefit.

In this context, the most useful model for market regulators would be the Cournot Model, which is within the concept of Nash Equilibrium. In this case, the strategic variables are the quantities offered, and prices are established according to the total quantity produced in the market, which are defined based on the aggregate demand of the sector. This one-stage game model does not take repeated actions into account. Through the Cournot Model, the market defines the price and quantity of electricity offered in bilateral contracts.

\subsection{The Cournot model or simultaneous determination of quantities (with two companies)}

The Cournot model derives its name from the French mathematician, philosopher and economist Antoine Augustin Cournot (1801-1877), who published in 1838 an analysis about the behavior of two companies which simultaneously decided their production yield. (FIANI, 2015).

This model represents the market analysis of a few companies, that is, oligopolies. This article will demonstrate the game with two players: Solar 1 and Solar 2. The two companies produce solar energy to supply the national electricity market. Electricity is a homogeneous product, that is, consumers will not perceive the difference in the quality of the same and, therefore, base their decisions on which product to acquire considering only the price, independent of the generator.

As a behavioral hypothesis, it will be admitted that each company seeks to maximize its profit. A company's profit is the difference between its revenue and its costs. It is necessary to define the revenue and cost of each company, so as to construct a reward function for each one of them.

Revenue is the product of the market price by the quantity sold by each company. Assuming that the market price is given by a linear demand function, as in the following Equation 1:

$p(q)=A-b\left(q_{1}+q_{2}\right)$

Where $p(q)$ is the market price as a function of quantity, $q$ is the total quantity produced and sold on the market, $A$ and $b$ are constants, $q_{1}$ is the quantity produced by Solar 1 and $q_{2}$ is the quantity produced by Solar 2 . Therefore, by Equation 2,

$q=q_{1}+q_{2}$

The total quantity produced and sold on the market, $A$ and $b$ total revenue $R T_{1}$ and Solar 2's $R T_{2}$ are given, respectively, by the Equations 3 and 4:

$$
\begin{aligned}
& R T_{1}=p(q) q_{1}=A q_{1}-b q_{1}^{2}-b q_{1} q_{2} \\
& R T_{2}=p(q) q_{2}=A q_{2}-b q_{1} q_{2}-b q_{2}^{2}
\end{aligned}
$$

To define the reward function of each company, it subtracts from the revenues the costs in order to obtain the profits of each company. To simplify, it will be adopted that the cost functions of the two companies $C_{1}$ and $C_{2}$ are identical and given by the Equations 5 and 6:

$C_{1}=c q_{1}$

$C_{2}=c q_{2}$

Where $c$ is a constant strictly higher than zero. In the sequence, one can observe the reward function of each company, that is, the profits $\pi_{1}$ and $\pi_{2}$ as being:

$$
\begin{aligned}
& \pi_{1}=A q_{1}-b q_{1}^{2}-b q_{1} q_{2}-c q_{1} \\
& \pi_{2}=A q_{2}-b q_{1} q_{2}-b q_{2}^{2}-c q_{2}
\end{aligned}
$$

Then, the first derivative of each of the Equations 7 and 8 is made in relation to $q_{1}$ and, respectively, and equals zero, according to the first-order condition for maximization:

$$
\begin{aligned}
& \frac{\partial \pi_{1}}{\partial q_{1}}=A-2 b q_{1}-b q_{2}-c=0 \\
& \frac{\partial \pi_{2}}{\partial q_{2}}=A-b q_{1}-2 b q_{2}-c=0
\end{aligned}
$$

Putting $q_{1}$ and $q_{2}$ in evidence in the Equations 9 and 10 , respectively, two new equations are created:

$$
\begin{aligned}
& q_{1}=\frac{A-b q_{2}^{e}-c}{2 b} \\
& q_{2}=\frac{A-b q_{1}^{e}-c}{2 b}
\end{aligned}
$$

Equations 11 and 12 describe how much each of the companies will produce to maximize their profits given the expected output of their competitor. The fact that the quantity produced is as expected is indicated by the superscript $e$.

The expected production is used because each company makes its decision on how much to produce without knowing the decision of the other company, since it is a simultaneous game. The two equations provide the reaction functions of the Solar 1 and Solar 2 companies respectively. The amount that the company will produce will be its best response to the decision that it expects its competitor to take. 


\section{RESULTS AND DISCUSSIONS}

\subsection{Application of Cournot's model with two companies}

Nowadays, there are several possibilities of applications of the Theory of Games in the commercialization of electric energy by an agent of the sector, among which we can mention: competitive bargaining, Nash's cooperative bargain, oligopolistic models, among others. Each of them can be used for a specific purpose, such as expansion in generation, participation in electric power auctions, preparation of auctions to purchase equipment, among other applications that vary as market regulations are determined. The application of these concepts, for the purpose of maximizing the profit of a particular company, are usually not published for strategic reasons.

In time, it will be presented a hypothetical example of two companies (duopoly), Solar 1 and Solar 2, that use the Cournot method to exemplify the maximization of the profit of both, using the model for the two companies. These companies do not cooperate, and have the same marginal cost, ie the same production technology and access to energy. Given that the demand function of the companies' market $P$ is given by:

$P=90-Q$

Considering the marginal costs $C_{1}$ and $C_{2}$ in the Equation 14, it has:

$c_{1}=c_{2}=3$

And, in this case, fixed costs are equal to zero. First, we must adopt $\frac{\partial \pi_{i}}{\partial q_{i}}=0$ and, from this rule, it is possible to determine how much energy each company will produce to maximize profit. Starting with Solar 1, it is assumed that profit is:

$$
\begin{aligned}
& \pi_{1}=R_{t 1}-C_{t 1} \\
& R_{t 1}=P q_{1} \\
& C_{t 1}=C_{F 1}+C_{V 1}
\end{aligned}
$$

Where, $R_{t 1}$ and $C_{t 1}$ are total revenue and cost of Solar 1, respectively, $C_{F 1}$ and $R_{V 1}$ are the fixed and variable costs of Solar 1, respectively. Therefore, replacing the Equations 16 and 17 in the Equation 15, we have:

$\pi_{1}=P_{q 1}-\left(C_{F 1}+C_{V 1}\right)$

According to Equation 13, it is possible that the demand can be considered by the quantity that the companies Solar 1 and Solar 2 will produce, this can be represented by the Equation 19:

$$
Q=q_{1}+q_{2}
$$

Given that the fixed cost is equal to zero, and the variable cost is equal to the marginal cost multiplied by the amount of energy that each company produces, we have that the profit of Solar 1 is represented by the Equation 20, based on the Equation 18:

$$
\pi_{1}=P q_{1}-\left(0+3 q_{1}\right)
$$

By factoring the terms, one obtains:

$$
\pi_{1}=q_{1}(P-3)
$$

Replacing the Equation 13 in the Equation 21, we have:

$$
\pi_{1}=q_{1}(90-Q-3)
$$

Substituting the Equation 19 into the Equation 22, we have:

$$
\pi_{1}=q_{1}\left(90-\left(q_{1}+q_{2}\right)-3\right)
$$

Developing:

$$
\pi_{1}=87 q_{1}-q_{1}^{2}-q_{1} q_{2}
$$

Finding the maximum point of Equation 24, that is, deriving from the $q_{1}$ and equaling to zero, we have:

$$
\frac{\partial \pi_{1}}{\partial q_{1}}=87-2 q_{1}-q_{2}=0
$$

Organizing and isolating the terms, we have the reaction function of Solar 1:

$q_{1}=\frac{87-q_{2}}{2}$

Taking into account that Solar 2, by analogy, is identical to Solar 1 because they produce the same product, electric energy through solar energy, and have the same marginal costs, it can be assumed that the Solar 2 reaction function will be:

$q_{2}=\frac{87-q_{1}}{2}$

Replacing the Equation 27 in the Equation 26, you have:

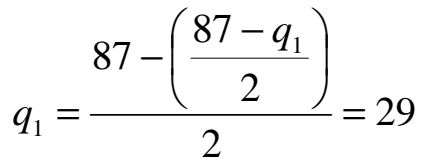

It should be noted that the value of $q_{1}$ represents the amount of energy that Solar 1 can produce to maximize its profit given its dependency on Solar 2. To find the value that Solar 2 should produce, the value of $q_{1}$ must be substituted in the Equation 27:

$q_{2}=\frac{87-q_{1}}{2}=\frac{87-29}{2}=29$ 
After finding the amounts of energy that each company must produce, one must find the price that will cost the unit of energy. This is obtained by the Equations 19 and 13:

$$
\begin{gathered}
Q=q_{1}+q_{2}=29+29=58 \\
P=90-Q=90-58=32
\end{gathered}
$$

Through the above data, it is possible to calculate the profit of each company. The same is given by the Equation 21:

$\pi_{1}=q_{1} \times(P-3)=29 \times(32-3)=841$ equal:

By Cournot's Theorem, the profit of each company is $\pi_{1}=\pi_{2}=841$

In Table 1, it is possible to visualize the summary of the results found in the development of this work:
Table 1 - Summary of the results of the companies Solar 1 and Solar 2.

\begin{tabular}{lll}
\multicolumn{1}{c}{ Item } & \multicolumn{1}{c}{ Solar 1 } & \multicolumn{1}{c}{ Solar 2 } \\
Fixed costs $(\mathrm{R} \$)$ & $\mathrm{R} \$ 0,00$ & $\mathrm{R} \$ 0,00$ \\
\hline Marginal costs $(\mathrm{R} \$ / \mathrm{kW})$ & $\mathrm{R} \$ 3,00$ & $\mathrm{R} \$ 3,00$ \\
\hline $\begin{array}{l}\text { Amount of energy produced } \\
(\mathrm{kW})\end{array}$ & 29,0 & 29,0 \\
\hline Sales price $(\mathrm{R} \$ / \mathrm{kW})$ & $\mathrm{R} \$ 32,00$ & $\mathrm{R} \$ 32,00$ \\
\hline Profit $(\mathrm{R} \$ / \mathrm{kW})$ & $\mathrm{R} \$ 841,00$ & $\mathrm{R} \$ 841,00$ \\
\hline
\end{tabular}

From the Equations 26 and 27, it is possible to calculate the respective amounts of energy of each company. In Table 2, it is possible to visualize the amounts of energy produced.

Table 2 - Summary of energy produced by Solar 1 and Solar 2.

\begin{tabular}{cccc}
\multicolumn{2}{c}{ Solar $\mathbf{1}$} & \multicolumn{2}{c}{ Solar 2} \\
\hline $\boldsymbol{q}_{\mathbf{1}}(\mathbf{k W})$ & $\boldsymbol{q}_{\mathbf{2}}(\mathbf{k W})$ & $\boldsymbol{q}_{\mathbf{1}}(\mathbf{k W})$ & $\boldsymbol{q}_{\mathbf{2}}(\mathbf{k W})$ \\
0,0 & 87,0 & 0,0 & 43,5 \\
23,5 & 40,0 & 40,0 & 23,5 \\
29,0 & 29,0 & 29,0 & 29,0 \\
43,5 & 0,0 & 87,0 & 0,0 \\
\hline
\end{tabular}

Figure 1 shows the graphical representation of the Reaction Functions of Solar 1 and Solar 2.

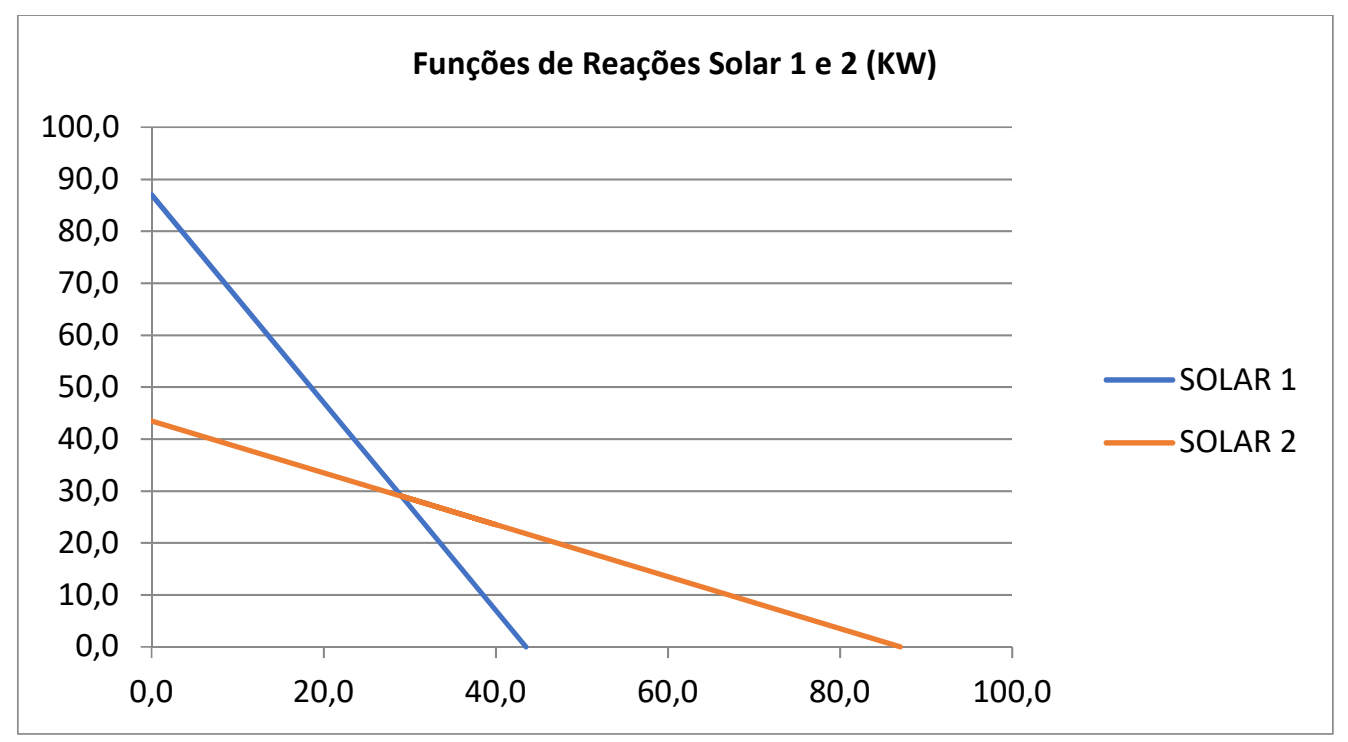

Figure 1 - Reaction Functions of Solar 1 and Solar 2.

At the moment that the companies produce the same amount of electric energy, the Cournot-Nash equilibrium is shown, at this point, both use the functions of reaction of better response to the market. The competition between Solar 1 and Solar 2, that is to say, a duopoly, makes the amount of energy offered exceeds in the market in relation to the situation of a monopoly, that is, only a company producing energy for supply. The energy price exceeds the marginal cost, but it is lower than in the situation of a monopoly.

\section{FINAL CONSIDERATIONS}

The Game Theory can be used in two distinct perspectives in an electric power market. The vision used in the present study was of two agents that have the same objective of maximizing its profits.

In the hypothetical situation presented, the Game Theory was applied to predict the strategies of two companies, Solar 1 
and Solar 2, based on information they have about the market. The model used was that of Cournot, which is within the concept of Nash equilibrium. Through this model it was possible to define the price and quantity of electric energy to be offered to consumers.

The use of the Cournot model, in this hypothetical case, has shown that the market is in balance, as the companies Solar 1 and Solar 2 have chosen to maximize their respective profits, taking into consideration that none will change the supply behavior in the market. It has been proven that the duopoly

\section{REFERENCES}

FIANE, R. Teoria dos Jogos. 4 eds., Rio de Janeiro: Elsevier, 2015.

FIGUEIREDO, R. S. Teoria dos Jogos: Conceitos, Formalização Matemática e aplicação à Distribuição de Custo Conjunto. Gestão e Produção (UFSCar), São Carlos, v. 1, n.3. 1994.

LANZOTTI, C. R.; CORREIA, P. B.; SILVA, A. J. Comercialização de energia: experiências internacionais e brasileira. In: anais do IX CONGRESSO BRASILEIRO DE ENERGIA, Rio de Janeiro, 2002.

NEUMANN, J.; MORGENSTERN, O. R. Theory of Games and Economic Behavior. Princeton University Press, 1972. makes the amount of energy offered rise in the market as opposed to a monopoly, that is, only a company producing energy for supply. In addition, for this configuration, the price of energy is lower than in the situation of a monopoly, even exceeding the marginal cost.

In this way, it can be concluded that the Game Theory produces benefits in the teaching and learning process, favoring cognitive aspects and taking the teaching in a differentiated and playful way. 